\title{
Un comentario a propósito del art. 68. 4 de la Ley de Procedimiento Administrativo Común y de la sentencia de casación de la sala tercera del tribunal supremo núm. 954/2021, de 1 de julio
}

\section{A comment in relation to article 68.4 from administrative procedure common and judgment of casation of third room the Supreme Court 954/2021, 1st of July}

\author{
Mariano López Benítez \\ Universidad de Córdoba (España) \\ ORCID: https://orcid.org/0000-0002-3850-1885 \\ mariano.lopez@uco.es
}

\section{NOTA BIOGRÁFICA}

Mariano López Benítez es Doctor en Derecho por la Universidad de Córdoba con Premio Extraordinario. Catedrático de esta misma Universidad, es autor de monografías y trabajos de investigación relacionados tanto con la denominada parte general como la llamada parte especial del Derecho Administrativo.

Patricia Soriano Bautista Universidad de Córdoba (España) ORCID: https://orcid.org/0000-0002-5693-3518 patricia.soriano@hotmail.com

\section{NOTA BIOGRÁFICA}

Patricia Soriano Bautista es funcionaria del Cuerpo de Administradores de Gestión Financiera de la Junta de Andalucía. En la actualidad, es doctoranda del Programa de Ciencias Sociales y Jurídicas de la Universidad de Córdoba, realizando su tesis doctoral sobre la Administración electrónica.

\section{RESUMEN}

EI TS, en su reciente sentencia 954/2021, de 1/7, aborda por vez primera la interpretación del complejo art. 68.4 LPAC. Por las características del caso, el TS considera que las consecuencias reseñadas por ese precepto no son aplicables a los procedimientos revisorios. Sin embargo, son muchas las dudas interpretativas que el art. 68.4 continúa planteando y que son analizadas al hilo de este comentario.

\section{PALABRAS CLAVE}

Procedimiento administrativo; Administrado; Solicitud; Subsanación; Administración Electrónica.

\section{ABSTRACT}

The Supreme Court, in its recent judgment 954/2021, of July 1, addresses for the first time the interpretation of the complex article 68.4 LPAC. Due to the characteristics of the case, the Supreme Court considers that 
REALA. Nueva Época - N. 16, octubre 2021 - ISSN: 1989-8975 - DOI: https://doi.org/10.24965/reala.i16.10990 - [Págs. 134-149]

Un comentario a propósito del art. 68. 4 de la Ley de Procedimiento Administrativo Común y de la sentencia de casación de la sala...

Mariano López Benítez / Patricia Soriano Bautista

the consequences outlined by this provision are not applicable to review procedures. However, there are many interpretative doubts that Article 68.4 continues to raise and are analyzed in line with this commentary.

\section{KEYWORDS}

Administrative procedure; Administered; Request form; Correction; Electronic administration.

\section{SUMARIO}

1. PLANTEAMIENTO. 2. POSICIONES JURISPRUDENCIALES ENTORNOALART. 68.4 LPAC. 3. CUESTIONES PLANTEADAS EN CASACIÓN PARA FORMACIÓN DE DOCTRINA: ANÁLISIS CRÍTICO. 4. REFLEXIONES FINALES. REFERENCIAS BIBLIOGRÁFICAS.

\section{PLANTEAMIENTO}

La reciente Sentencia de la Sección $3 .^{\text {a }}$ de la Sala Tercera del Tribunal Supremo núm. 954/2021, de 1 de julio de 2021 (recurso de casación núm. 1928/2020. ECLI:ES:TS:2021:2747) ha efectuado un primer e importante pronunciamiento, que creemos no va a ser el único, sobre la interpretación del art. 68.4 de la Ley 39/2015, de 1 de octubre, de Procedimiento Administrativo Común (LPAC). Un precepto, expresión de la decidida apuesta hecha por la LPAC en favor de la efectiva implantación de la Administración electrónica, que, no obstante, puede plantear -está suscitando ya- serios conflictos desde el punto de vista de las garantías de los administrados ${ }^{1}$. Como se recordará, sostiene el mencionado precepto que.

1 Habida cuenta la naturaleza de comentario eminentemente jurisprudencial que tiene el presente trabajo, deliberadamente se ha tratado de no desviar la atención del lector recurriendo a una proliferación excesiva de citas. Por ello, se han reducido estas al mínimo y hemos optado porque lo sean de fragmentos de la propia sentencia comentada o se refieran a la jurisprudencia de los Tribunales Superiores de Justicia recaída sobre la interpretación del art. 68.4 LPAC, en la medida en que esta jurisprudencia dibuja el cuadro ante el que se encuentra el Tribunal Supremo a la hora de dilucidar la cuestión que se le somete en casación.

Aun así, nos parece conveniente dejar constancia de que, tal vez, la polémica doctrinal más viva es la que al respecto han mantenido en las redes Gómez Fernández (2018), por una parte, y Chaves García (2018). El primero de ellos abogó por una interpretación restrictiva del precepto basándose en tres argumentos, a saber: $1 .^{\circ}$ que otra interpretación iría en contra sobre el carácter garantista y antiformalista del procedimiento administrativo, significando a la postre una conculcación del derecho a la tutela judicial efectiva; $2{ }^{\circ}$ que una interpretación literal del precepto abocaría a «una especie muy rara de subsanación, puesto que ha sido una característica de la subsanación de la solicitud en un procedimiento administrativo, el carácter retroactivo de la misma, de modo que una vez subsanada la irregularidad formal, se tiene como fecha de presentación la de la solicitud y no la de la subsanación»; y $3 .^{\circ}$ que la interpretación restrictiva se deriva del propio tenor literal del art. 68.4 LPAC: «cuando el art. 68.4 de la Ley 39/2015 dice que se considerará como fecha de presentación de la solicitud aquélla en la que haya sido realizada la subsanación añade al inicio de la frase otra que la puntualiza, a estos efectos. Si leemos la frase anterior, cuando dice a estos efectos se está refiriendo a la presentación electrónica, con lo que uniendo ambas frases, nos encontramos con lo que quiere decir el artículo es que a los efectos de la presentación electrónica, se considerará como fecha de presentación de la solicitud aquella en la que haya sido realizada la subsanación, que es cuando realmente se produce la presentación electrónica y no antes, cuando la misma no se había realizado». Por lo que, a la postre, lo que significa, en opinión de este autor, es que es, a partir del momento de la subsanación electrónica, se iniciará el cómputo de los plazos de los que la Administración dispone para resolver. Tales inconvenientes eran, en suma, los que, como síntesis, le llevaban a pedir la eliminación del precepto controvertido.

Frente a la opinión sucintamente expuesta de Gómez Fernández, J. R. Chaves mantenía la oportunidad y literalidad del precepto, puesto que, por un lado, una interpretación que prescindiese de los términos literales del art. 68.4 sería una interpretación contra legem; y, porque, de otra parte, abonar otra interpretación diferente supondría premiar la torpeza y negligencia de los obligados a relacionarse electrónicamente con la Administración, puesto que «a donde no alcanza ni debe alcanzar la subsanación es a reabrir un plazo material de acreditación del derecho, ni a ofrecer una situación de ventaja en procedimientos competitivos ni a convertir un plazo formal uniforme y predeterminado en un plazo flexible y a la carta».

Con ocasión de la publicación de la sentencia de casación del TS, que aquí comentamos, ambos autores han vuelto sobre el tema dando noticia de los términos de la sentencia (Gómez Fernández, 2021, y Chaves García, 2021). A ellos, se ha añadido también, dando noticia de la referida sentencia, Aparicio (2021). A estos tres comentarios de urgencia de la sentencia debe sumarse por su interés intrínseco y por el hecho de que el Letrado que ha actuado en el recurso de casación en representación de la parte recurrida (la Confederación de Organizaciones Empresariales de Castilla y León) ha sido D. José Ángel Castillo Cano-Cortés, la entrevista que, tanto a él como a su compañero de despacho, D. Luis Zafra Romero, se les hace en Confilegal.com, 16 de julio de 2021 , bajo el título "El Supremo aclara que, aunque se subsane electrónicamente el recurso presentado, el plazo computable es el del primer escrito". También de Zafra Romero (2020, p. 9) es relevante el comentario que firmó antes sobre la cuestión.

Al margen de lo expuesto y sin ánimo exhaustivo, se hallan referencias también a los problemas suscitados por el art. 68.4 en los comentarios generales a la LPAC. Por ejemplo, Rego Blanco (2017, p. 1049), opina que «en este precepto subrepticiamente se incluye una nueva causa de inadmisión registral para todos los registros presenciales». Más recientemente, de la Cruz Ferrer y Trujillo Pérez 
REALA. Nueva Época - N. 16, octubre 2021 - ISSN: 1989-8975 - DOI: https://doi.org/10.24965/reala.i16.10990 - [Págs. 134-149]

Un comentario a propósito del art. 68. 4 de la Ley de Procedimiento Administrativo Común y de la sentencia de casación de la sala...

Mariano López Benítez / Patricia Soriano Bautista

«Si alguno de los sujetos a los que hace referencia el artículo 14.2 y 14.3 presenta su solicitud presencialmente, las Administraciones Públicas requerirán al interesado para que la subsane a través de su presentación electrónica. A estos efectos, se considerará como fecha de presentación de la solicitud aquella en la que haya sido realizada la subsanación».

La simple lectura del precepto transcrito lo convierte probablemente en la consecuencia jurídica más llamativa del deber u obligación establecidos por los apartados $2 .^{\circ}$ y $3 .^{\circ}$ del art. 14 . No es la consecuencia jurídica única, pero sí es, sin duda, la que despierta más atención y la que más prontamente está planteando problemas hermenéuticos de gran calibre hasta el punto de haber dado ya lugar, con anterioridad a este fallo del Tribunal Supremo, a decisiones contradictorias de diversos Tribunales Superiores de Justicia.

La STS 954/2021, cuyo Ponente ha sido el Magistrado Bandrés Sánchez-Cruzat, trae causa del recurso de casación suscitado contra la Sentencia de la Sección Primera de la Sala de lo ContenciosoAdministrativo del Tribunal Superior de Justicia de Castilla y León, con sede en Valladolid, de 24 de octubre de $2019^{2}$. Esta última había estimado parcialmente el recurso contencioso-administrativo planteado por la Confederación de Organizaciones Empresariales de Castilla y León contra la Resolución de la Consejería de Economía y Hacienda de la Junta de Comunidades de Castilla y León de 20 de julio de 2018 por la que se había inadmitido el recurso de alzada interpuesto contra el Acuerdo de la Dirección General de Comercio y Consumo de 22 de mayo de 2018 mediante el que se convocaban elecciones para la renovación de los órganos de gobierno de las Cámaras Oficiales de Comercio, Industria y Servicios de la Comunidad de Castilla y León. En lo que al presente comentario importa, la razón de que, por parte de la Administración autonómica, se inadmitiese el recurso de alzada instado contra el acuerdo de convocatoria de elecciones, radica en que la mencionada alzada se presentó en el Registro de forma presencial el último día del plazo establecido para ello: esto es, el 28 de junio de 2018, toda vez que el acuerdo de convocatoria se había publicado en el Boletín Oficial de Castilla y León núm. 101, de 28 de mayo de 2018. Como, según el criterio de la Administración autonómica, la recurrente, en tanto que persona jurídica, devenía obligada a presentar el recurso telemáticamente por ministerio de lo dispuesto en el art. 14.2 a) LPAC, la requirió electrónicamente el día 3 de julio para que subsanase tal defecto de presentación, extremo que la interesada cumplimentó telemáticamente al siguiente día.

Tal argumentación es la que reproduce la representación de la Administración Autonómica en su contestación a la demanda de cara a la inadmisión del recurso contencioso-administrativo. Empero, el TSJ la rechaza invocando y remitiéndose tanto a lo ya dicho en su anterior Sentencia de 28 de octubre de 2018, como a los argumentos mantenidos por la STSJ de Madrid de 29 de mayo de $2018^{3}$. En esencia, los razonamientos de los que el TSJ de Castilla y León se vale en su fundamento de derecho segundo para rechazar la inadmisión del recurso discurren por una doble vía. En primer lugar, considera que requerir al interesado

(2021, p. 442), tras hacerse eco de la polémica registrada en las redes anotada más arriba, sintetizan la posición del legislador de una manera muy gráfica: «El legislador ha tratado en este punto de dar con el palo (la fecha de presentación será la de la subsanación) para que los ciudadanos se acostumbren a comer la zanahoria (relacionarse electrónicamente con la Administración)».

2 STSJ núm. 1252/2019, de 24 de octubre, Sala de lo Contencioso de Valladolid, recurso contencioso-administrativo núm. 1138/2018, Ponente: Fresneda Plaza, ECLI:ES: TSJCL:2019:4490.

3 STSJ de Madrid núm. 276/2018, de 29 de mayo, recurso 251/2017, Ponente: Rivas Moreno, ECLI:ES: TSJM:2018:7644. Interesa reproducir lo que el TSJ señala: «Cuando se requiere la subsanación de un defecto, concediéndole un plazo de 10 días para su subsanación, y se le apercibe de tenerle por desistido de su pretensión, implícitamente, se está considerando dicho defecto subsanable. Y por subsanación debe entenderse la de considerar el escrito (el primer escrito) subsanado. Lo que conlleva tener como fecha de presentación, la del escrito presentado de forma presencial. Llama la atención que la Administración haya declarado inadmisible el recurso, a pesar de que por actos propios lo tuvo ya por presentado, advirtiendo a la parte, únicamente, de que se le tendría por desistido de su pretensión, en caso de no cumplimentar el requerimiento (de presentación telemática del escrito, en el plazo de diez días hábiles) (...) La inadmisión del recurso de alzada presentado en el plazo concedido, y en la forma ordenada en el requerimiento, infringe la confianza del administrado que se atiene estrictamente a las instrucciones de la Administración».

Más adelante, en su fundamento de derecho séptimo, el TSJ es aún más concluyente, ya que pone de relieve tanto la impropiedad de aplicar el plazo de 10 días del apartado $2 .^{\circ}$ del art. 68 al apartado $4 .^{\circ}$, como el absurdo que representa otorgar un plazo de subsanación si la fecha que se tomará en cuenta, a efectos de la correcta presentación en plazo del escrito, será la de la presentación telemática: «Porque el artículo 68 sólo establece el plazo de 10 días hábiles de subsanación en el párrafo primero; previendo este plazo como un período en el que se admite propiamente la posibilidad de subsanar el defecto apreciado, con todos los efectos legales; lo que establece de forma coherente con la obligación de indicar al requerido que, en caso de no cumplimentación de lo ordenado se le tendrá por desistido de su pretensión. Por el contrario, el párrafo cuarto no menciona plazo alguno de subsanación, y es que, ni existe, ni es necesario. Porque si la fecha de presentación del escrito que se va a considerar, en todo caso, va a ser la de su presentación telemática, no se trata de una subsanación propia, ya que la consecuencia del defecto es, de entrada, la de no tener por presentado el escrito. Y, por otra parte, la fijación de un plazo concreto para su presentación resulta inútil, pues, cuando se realice, esto es, cuando se presente de forma telemática, sin perjuicio del tiempo en que se haga, producirá los efectos que procedan». 
REALA. Nueva Época - N. 16, octubre 2021 - ISSN: 1989-8975 - DOI: https://doi.org/10.24965/reala.i16.10990 - [Págs. 134-149]

Un comentario a propósito del art. 68. 4 de la Ley de Procedimiento Administrativo Común y de la sentencia de casación de la sala...

Mariano López Benítez / Patricia Soriano Bautista

para que subsane la falta de presentación electrónica del recurso contraría la doctrina de los actos propios de la Administración. En este punto, el seguimiento de la decisión del TSJ madrileño es absoluta, reproduciendo íntegramente las ideas expuestas por este último órgano jurisdiccional:

«Cuando se requiere la subsanación de un defecto, concediéndole un plazo de 10 días para su subsanación, y se le apercibe de tenerle por desistido de su pretensión, implícitamente, se está considerando dicho defecto subsanable. Y por subsanación debe entenderse la de considerar el escrito (el primer escrito) subsanado. Lo que conlleva tener como fecha de presentación, la del escrito presentado de forma presencial.

Llama la atención que la Administración haya declarado inadmisible el recurso, a pesar de que por actos propios lo tuvo ya presentado, advirtiendo a la parte, únicamente, de que le tendría por desistido de su pretensión, en caso de no cumplimentar el requerimiento (de presentación telemática del escrito, en el plazo de diez días hábiles)».

Por ello, extrayendo las consecuencias de esta argumentación para el caso objeto de la Litis, el TSJ de Castilla y León proclama que «una interpretación tan restrictiva como la planteada por la Administración, vulneraría los principios antiformalistas, y de subsanabilidad con gran raigambre en nuestro ordenamiento jurídico», ya que «la posible subsanación que se lleva a efecto no puede privar de validez al acto originario del particular que adoleciera de algún tipo de deficiencia».

El otro argumento empleado por el TSJ de Castilla y León combina dos ideas: una primera, atañe al marco de intemporalidad de la LPAC. Como el plazo originario para la entrada en vigor de las previsiones relativas al Registro electrónico, establecido por la Disposición final 7. ${ }^{a}$ LPAC, se vio prorrogado hasta el 2 de octubre de 2020 por fuerza del Real Decreto-Ley 11/2018, de 31 de agosto, la obligación de presentar electrónicamente las solicitudes ante la Administración, en tanto subordinada a la efectiva implantación del Registro electrónico, resultaba también diferida al momento en que finalizase el plazo de prórroga de la entrada en vigor de las determinaciones relativas al Registro electrónico y no era, por tanto, exigible en el tiempo en el que se desarrolla la litis origen del presente proceso contencioso-administrativo.

Por otro lado, el TSJ de Castilla y León, aun sin explicitarlo claramente, mas haciendo suyo lo expresado en su anterior sentencia de 29 de mayo de $2019^{4}$, desliza una idea muy interesante sobre la que habremos de volver más adelante: la de considerar que, en todo caso, las consecuencias jurídicas expresadas por el art. 68.4 LPAC quedarían constreñidas únicamente a los escritos del administrado que tuviesen la condición de solicitudes iniciales, pero no a los recursos administrativos:

«A análoga conclusión se llegó en la sentencia de esta Sala de 29 de mayo de 2019, recurso $122 / 2018$, en la que se expresa que el artículo 68 se ubica dentro del Título IV, dedicado al procedimiento administrativo, y, más concretamente, en la Sección $3 .^{a}$, que se refiere a la iniciación del procedimiento a solicitud del interesado. No es el caso en el que nos encontramos,

4 STSJ de Castilla y León, sede de Valladolid, núm. 806/2019, de 29 de mayo (rec. 122/2018), Ponente: Blanco Domínguez, ECLI:ES: TSJCL:2019:2546. El caso examinado por esta sentencia se refiere a un supuesto en el que la Administración forestal autonómica había declarado de utilidad pública e inscrito en el Catálogo de Montes de la provincia de Burgos el Monte «Arrate», propiedad del Ayuntamiento de Valle de Mena. La Orden de Inscripción, publicada en el Boletín Oficial de Castilla y León de 26 de julio de 2017, Tras la solicitud de cierta documentación, necesaria para la presentación de recurso, la Entidad Local Menor de Anzo de Mena-Valle de Mena presentó recurso de reposición en una oficina de correos en fecha 20 de septiembre de 2017 . El 16 de octubre es requerida de subsanación para que en el plazo de 10 días presentase el recurso por vía electrónica, requerimiento notificado el 26 de octubre y atendido el 6 de noviembre de 2017. La Orden de 7 de marzo de 2018, que es la recurrida, declara inadmitido el recurso de reposición en virtud de lo preceptuado por los arts. 14.2 a) y 68.4 LPAC.

EI TSJ refuta la pretensión de que se inadmita el recurso por versar sobre un acto firme con las siguientes palabras, que, en gran parte, son las que hace suyas la decisión objeto del presente comentario: «La Administración interpreta este artículo en el sentido de que, si la solicitud no se presenta electrónicamente, la fecha en que la misma ha de tenerse por presentada es la fecha en la que, tras el requerimiento que prevé ese artículo, se presenta electrónicamente, sin poder atender a la fecha en que se hizo de manera presencial infringiendo la obligación que tiene el interesado de relacionarse electrónicamente con la Administración. A la vista de las circunstancias concurrentes, dicha interpretación no puede compartirse por las siguientes razones. En primer lugar, el artículo 68 se ubica dentro del Título IV, dedicado al procedimiento administrativo, y, más concretamente, en la Sección $3 .^{a}$, que se refiere a la iniciación del procedimiento a solicitud del interesado. No es el caso en el que nos encontramos, ya que el escrito que la Administración considera extemporáneo no es de iniciación de ningún procedimiento, sino que es un recurso de reposición que no da inicio a ningún procedimiento. El art. 14.2 de la Ley 30/2015 (...) no se establece ninguna consecuencia para el caso de que se incumpla esa obligación, presentando presencialmente un recurso, y no cabe hacer una interpretación extensiva del artículo 68.4 porque el mismo claramente se aplica a los efectos que el mismo acota, esto es, a los efectos de determinar la fecha de presentación de solicitudes. En los artículos 112 y siguientes de la Ley 39/2015 no hay una previsión semejante a la contenida en el artículo 68.4». 
REALA. Nueva Época - N. 16, octubre 2021 - ISSN: 1989-8975 - DOI: https://doi.org/10.24965/reala.i16.10990 - [Págs. 134-149]

Un comentario a propósito del art. 68. 4 de la Ley de Procedimiento Administrativo Común y de la sentencia de casación de la sala...

Mariano López Benítez / Patricia Soriano Bautista

ya que el escrito que la Administración considera extemporáneo no es de iniciación de ningún procedimiento, sino que es un recurso de reposición que no da inicio a ningún procedimiento».

Ciertamente, la idea es sugerente, pero no deja de plantear algunas dudas tanto sobre la naturaleza autónoma o, por el contrario, subordinada de los procedimientos administrativos de recurso, como con respecto al papel integrador que las disposiciones comunes del Título IV desempeñan en relación con la generalidad de los procedimientos administrativos, aspecto éste sobre el que la sentencia de casación no se pronuncia.

\section{POSICIONES JURISPRUDENCIALES EN TORNO AL ARTÍCULO 68.4 DE LA LPAC}

La sentencia del TSJ de Castilla y León, recurrida en casación, valiéndose en líneas generales de los argumentos empleados tanto por él como por otros Tribunales Superiores de Justicia, se inscribe claramente dentro de una línea jurisprudencial, todavía, en todo caso, no muy abundante, que amortigua los letales efectos a los que conduce la interpretación estricta de las consecuencias jurídicas previstas en el art. 68.4 LPAC con respecto al incumplimiento de la obligación de relacionarse electrónicamente con la Administración. Sin embargo, es necesario reconocer que no todas las decisiones jurisprudenciales recaídas sobre este precepto se han adscrito tan decididamente a esta corriente hermenéutica. Por el contrario, no faltan las que se han aferrado a los literales y rotundos términos del art. 68.4 y han aplicado su principal consecuencia jurídica sin mayores ambages.

Así sucede, por ejemplo, en el supuesto examinado por la STSJ de Madrid 15/2021, de 15 de enero ${ }^{5}$. La Mancomunidad Intermunicipal de Servicios Sociales del Este de Madrid (MISSEM) recurre en alzada el acuerdo de archivo de la comunicación relativa a la justificación de gastos correspondiente al período enero-febrero de 2018 del Convenio de Asistencia Integral y Multidisciplinar a las víctimas de género que tenía suscrito con la Comunidad de Madrid. Dicha certificación parcial se había presentado el antepenúltimo día del plazo de vencimiento por correo postal, teniendo entrada en el Registro auxiliar de la Consejería de Políticas Sociales y Familia el último día del plazo establecido para la presentación de la justificación de los gastos realizados durante el citado período. La Administración autonómica, considerando lo que establece el art. 3.2 LRJSP con respecto a la obligación de relacionarse electrónicamente las Administraciones Públicas, le aplica en su mayor rigor las consecuencias jurídicas previstas por el art. 68.4 LPAC, estimando incluso que ni tan siquiera tiene sentido formularle requerimiento de subsanación por devenir absolutamente inútil e innecesario. EI TSJ avala por completo la conducta seguida por la Administración autonómica madrileña.

«...es hecho admitido que, de conformidad con la Cláusula novena del concreto Programa a que se refiere el plazo para la presentación de las certificaciones parciales de gastos acompañadas a la justificación de gastos archivada y no tramitada, es de un mes desde la finalización del período a justificar (28-02-2018), lo que en el caso de autos nos lleva al día 28-03-2018, que es precisamente el último día del mencionado plazo del mes citado, coincidiendo con la fecha en que tuvo entrada en el Registro Auxiliar de la Consejería de Políticas Sociales y Familia».

En su escrito de demanda, MISSEM alega que no se le había formulado requerimiento de subsanación con respecto al modo de la presentación tal y como, a su juicio, preceptúa el art. 68.4 LPAC, debiendo tenerse en cuenta para ello el día en que presentó la certificación en la oficina postal (26-03-2018) y no el del día de entrada en el Registro de la Administración autonómica (28-03-2018). EI TSJ rechaza con rotundidad esta alegación, estimando incluso que su admisión constituiría la comisión de un fraude legal:

«Sin embargo esta tesis, no puede ser aceptada. En primer lugar, porque parte de tener en cuenta una fecha (26-03-2018) en que incumplió el obligado modo de presentación de la documentación, por lo que, de aceptarlo la Administración demandada, estaría incurriendo en contradicción, al estimar que la presentación por correo administrativo no es medio válido de presentación, pero sí lo es a los efectos de subsanar su solicitud. Por ello, la fecha a considerar para aplicar la posibilidad de subsanación no puede ser otra que aquella en que tuvo entrada en el Registro Auxiliar de la Administración demandada (28-03-2018), porque es, precisamente, en dicha fecha en la que pudo tener conocimiento de aquellas certificaciones parciales de justificación de gasto.

5 STSJ de Madrid núm. 15/2021, de 15 de enero, recurso núm. 78/2019, Ponente: Galindo Gil. ECLI:ES: TSJM: 2021:761. 
REALA. Nueva Época - N. 16, octubre 2021 - ISSN: 1989-8975 - DOI: https://doi.org/10.24965/reala.i16.10990 - [Págs. 134-149]

Un comentario a propósito del art. 68. 4 de la Ley de Procedimiento Administrativo Común y de la sentencia de casación de la sala...

Mariano López Benítez / Patricia Soriano Bautista

La consecuencia no es otra que, en aplicación del artículo 68.4 de la Ley 39/2015, se debería tener en cuenta la fecha en que se realizó la subsanación y teniendo en cuenta que la fecha inicial de entrada en la Dirección General de la Mujer fue el último día del plazo del que disponía la Mancomunidad Intermunicipal de conformidad con la cláusula novena del Convenio, sucedería que el requerimiento y la posterior subsanación se realizarían fuera del citado plazo de un mes, con la consecuencia de que la presentación de la justificación de gastos sería extemporánea» (Fundamento de derecho séptimo).

Similar razonamiento emplea el TSJ de Valencia ante un caso en el que un Ayuntamiento había presentado por correo postal el último día de plazo una solicitud de ayuda de saneamiento. EI TSJ considera incluso que abrir un trámite de subsanación, no sólo resulta inútil en el caso de autos, sino que además resultaría contrario al principio de celeridad del procedimiento administrativo, toda vez que «si lo hiciera la Administración estaría generando un trámite destinado a subsanar la forma de presentación de la solicitud, cuando, posteriormente, y para el caso de ser subsanada presentando la solicitud telemáticamente, necesariamente la tiene que considerar extemporánea» ${ }^{6}$.

En una situación intermedia entre ambas posiciones jurisprudenciales se colocan algunas otras sentencias que, sin pronunciarse directamente sobre las consecuencias jurídicas impuestas por el art. 68.4 LPAC, estiman que, sin embargo, éstas no resultan aplicables mientras se mantenga el régimen transitorio previsto por la Disposición final séptima de la LPAC. Exponente temprana de esta corriente es la STSJ de Castilla-La Mancha, sede de Albacete, núm. 504/2018, de 20 de diciembre de $2017^{7}$. Producida en apelación sobre una decisión del Juzgado de lo Contencioso-Administrativo núm. 2 de los de Albacete, desestimando el recurso contenciosoadministrativo planteado al amparo del procedimiento especial de protección jurisdiccional de los derechos fundamentales de la persona, los hechos de autos revisten un particular interés porque reflejan hasta qué punto el laberinto del proceso Kafkiano puede convertirse también entre nosotros y en nuestros días en una realidad.

La recurrente, una mercantil dedicada al alquiler de automóviles sin conductor, había sido requerida por el Ayuntamiento de Albacete para que identificase al conductor de un vehículo sancionado por la comisión de una infracción de tráfico. Atendiendo el requerimiento, la sociedad interesada comunica -con fecha 2-022017- la correspondiente identificación del conductor a través del Registro Electrónico Común (REC). No obstante, tal comunicación es rechazada porque el Ayuntamiento de Albacete no estaba adherido en aquel momento al Convenio del Sistema de Interconexión de Registros (SIR), razón por la que presenta la mencionada comunicación identificativa a través de una Oficina de Registro Administrativo de la Comunidad de Madrid. A los pocos días de ello (14-02-2017), el Servicio Administrativo de la Policía Local del Ayuntamiento de Albacete emite oficio de requerimiento de presentación electrónica de documentación, devuelve a la recurrente el escrito presentado presencialmente a fin de que en el plazo de diez días subsanase el requisito de la presentación telemática y le señala, en fin, que el Ayuntamiento de Albacete estaba utilizando la plataforma de la Administración electrónica de la Diputación de Albacete. La demandante vuelve a intentar la presentación telemática a través del REC (6-03-2017), volviendo a obtener el mismo motivo de rechazo que la vez anterior, por lo que al día siguiente pone de manifiesto mediante escrito presentado ante la Oficina de Correos, que ya había procedido a la identificación del conductor y que se le estaba colocando en una situación de indefensión. EI TSJ de Castilla-La Mancha estima la apelación formulada por la mercantil, anula la sentencia apelada y estima el recurso contencioso-administrativo interpuesto contra el Requerimiento de 14-02-2017 por cuya virtud se había proseguido el procedimiento sancionador contra la sociedad arrendataria de vehículos por no haber identificado en forma al conductor que cometió la infracción. EI TSJ considera que, aun tratándose de un acto de trámite, existe una clara conculcación del derecho de defensa, que legitima el recurso por esta vía excepcional del procedimiento especial de protección jurisdiccional de los derechos fundamentales, pues,

«...el Ayuntamiento de Albacete ni ha justificado el motivo o las causas por las cuales no se ha llevado a cabo [el Convenio con las plataformas y registros establecidos por la Administración del Estado], exigiendo, además, el cumplimentar la presentación telemática de escritos a través de su Sede Electrónica Municipal, sin dar opción al ciudadano de hacerlo desde el punto de acceso común/REC, y, por tanto, sin respetar lo establecido en la Disposición adicional segunda de la Ley 39/2015».

6 STSJ de Valencia núm. 93/2020, de 18 de febrero, ECLI:ES: TSJCV:2020:2533

STSJ de Castilla-La Mancha, sede de Albacete, núm. 504/2018, de 20 de diciembre de 2017, rec. apelación núm. 286/2017. Ponente: Estévez Goytre. ECLI:ES: TSJCLM:2017:3148. 
REALA. Nueva Época - N. 16, octubre 2021 - ISSN: 1989-8975 - DOI: https://doi.org/10.24965/reala.i16.10990 - [Págs. 134-149]

A ello, debe añadirse, según el TSJ, que la obligación de presentar telemáticamente los escritos aún no estaba vigente, teniendo, en cambio, plena vigencia lo establecido por el art. 38.4 de la Ley 30/1992 en lo relativo a la presentación de escritos, ya que «pese a que la Ley 39/2015 entró en vigor el 2 de octubre de 2016, las previsiones sobre este punto no producirán efectos hasta el día de 2 de octubre de $2018 »$.

La falta de vigencia de la obligación establecida por el art. 14.2 LPAC es también la razón que inspira a la STSJ de Valencia núm. 183/2020, de 24 de abril para estimar el recurso contencioso-administrativo deducido por una Comunidad de Propietarios contra la declaración de extemporaneidad de la acción de responsabilidad patrimonial interpuesta de manera presencial8:

«La Sala entiende que ha de darse la razón a la demandante. A la fecha de la presentación, por medio de la oficina de correos, de la reclamación de responsabilidad patrimonial -18 de enero de 2018- todavía no estaba vigente la obligación de presentación telemática de solicitudes, puesto que la disposición final séptima de la Ley 39/2015 establecía, en su redacción originaria, que las previsiones relativas al registro electrónico administrativo producían efecto a los dos años de la entrada en vigor de dicha ley, es decir, a partir del día 2 de octubre de 2018 (por Real Decreto-Ley 11/2018, de 31 de agosto, se ha modificado la referida disposición final séptima, quedando diferida la entrada en vigor de las previsiones sobre registro electrónico hasta el día 2 de octubre de 2020). Por tanto, en la fecha de presentación no telemática de aquella solicitud no se encontraba en vigor la exigencia regulada en el art. 14.2 de la Ley 39/2015 de relacionarse con las Administraciones Públicas a través de medios electrónicos para la realización de cualquier trámite de un procedimiento administrativo las personas jurídicas, los entes sin personalidad jurídica y determinadas personas físicas -en lo que aquí interesa, quienes ejerzan una actividad profesional para la que se requiera colegiación obligatoria, para los trámites y actuaciones que realicen con las Administraciones Públicas en ejercicio de dicha actividad profesional-, ni tampoco, por consiguiente, la previsión contenida en el art. 68.4 de la Ley $39 / 2015 »^{9}$.

Las expuestas son, por tanto, las tres líneas jurisprudenciales con las que la Sala $3 .^{a}$ del Tribunal Supremo se encuentra a la hora de resolver el recurso de casación suscitado contra la STSJ de Castilla y León de 24 de octubre de 2019. Una de ellas, la última que hemos reseñado, adquiere un valor meramente coyuntural, pues su virtualidad cesa - de hecho, ha cesado ya- cuando finaliza la vigencia de las sucesivas prórrogas de que ha sido objeto la Disposición final séptima de la LPAC en lo concerniente a la entrada en vigor de las disposiciones relativas a los registros electrónicos. Consecuentemente, desterrada esta interpretación, el dilema consiste en dilucidar cuál va a ser la línea argumentativa del Tribunal Supremo, si acogerá una de las dos reseñadas, o si, por el contrario, asumirá una línea propia integrada por elementos de una y otra corriente jurisprudencial. Es verdad que la respuesta a esta cuestión no es enteramente discrecional, sino que viene condicionada tanto por los términos en que viene planteado el propio recurso de casación como por la manera en que la Sección de Admisión del Tribunal Supremo formula la cuestión a la que debe dar respuesta la Sentencia del propio Tribunal.

\section{CUESTIONES PLANTEADAS EN CASACIÓN PARA FORMACIÓN DE DOCTRINA. ANÁLISIS CRÍTICO}

Desde este punto de vista, el Auto de la Sección de Admisión del Tribunal Supremo de 18 de diciembre de $2020^{10}$, que admite a trámite el recurso de casación planteado contra la sentencia del órgano jurisdiccional castellano-leonés, considera, en contra del criterio mantenido por el Letrado de los Servicios Jurídicos de la Comunidad Autónoma, que las cuestiones suscitadas por la decisión recurrida en relación con la interpretación del art. 68.4 LPAC no carecen de interés casacional objetivo en aras a la formación de jurisprudencia,

\footnotetext{
8 STSJ Valencia núm. 183/2020, de 24 de abril, rec. 62/2018, Ponente: Iruela Jiménez, ECLI:ES: TSJCV:2020:573.

9 Con argumentos similares, por ejemplo, la STSJ de Madrid núm. 48/2019, de 14 de febrero, rec. 113/2018, Ponente: Botella García-Lastra, ECLI:ES: TSJM:2019:1788.

10 Auto de la Sección de Admisión de la Sala 3. ${ }^{a}$ del Tribunal Supremo de 18 de diciembre de 2020, rec. cas. núm. 1928/2020, Ponente: Arozamena Laso, ECLI:ES:TS:2020:12753A.
} 
REALA. Nueva Época - N. 16, octubre 2021 - ISSN: 1989-8975 - DOI: https://doi.org/10.24965/reala.i16.10990 - [Págs. 134-149]

Un comentario a propósito del art. 68. 4 de la Ley de Procedimiento Administrativo Común y de la sentencia de casación de la sala...

Mariano López Benítez / Patricia Soriano Bautista

más aún cuando no existe todavía formada «jurisprudencia de esta Sala y parece conveniente un pronunciamiento al respecto» ${ }^{11}$. Así las cosas, las preguntas que, más en concreto y sobre este punto, se formula el Tribunal Supremo de cara a la formación de doctrina son dos:

«(i) Aclarar cuáles son las consecuencias que se derivan del requerimiento de subsanación que prevé el artículo 68.4 de la Ley 39/2015, de 1 de octubre, de Procedimiento Administrativo Común de las Administraciones Públicas cuando no se ha cumplido con la obligación de relación a través de medios electrónicos que impone el artículo 14.2 de la misma norma; en particular, si una vez subsanado el defecto y presentado el recurso por medios electrónicos, la subsanación es retroactiva (como entiende la Sala) o es la que fija el día en que ha de entenderse cumplimentado el trámite de que se trate.

(ii) Aclarar el régimen de vigencia de los mencionados preceptos, de acuerdo con lo establecido en la Disposición final séptima de la Ley 39/2015, de 1 de octubre».

Pese a lo que antes decíamos sobre la progresiva pérdida de interés de la cuestión relativa al momento de exigibilidad de la obligación de relacionarse electrónicamente con la Administración, lo cierto es que la Sección de Admisión formula sus preguntas sin excluirla, por lo que, en realidad, la mencionada Sección lo que está demandando es una respuesta general del Tribunal Supremo con respecto a todos los aspectos suscitados por la aplicación del art. 68.4 LPAC, y que han dado lugar, según hemos visto, a una jurisprudencia contradictoria por parte de los Tribunales Superiores de Justicia. No obstante, debe ya aclararse que la Sentencia del Tribunal Supremo elude pronunciarse deliberadamente sobre el régimen de vigencia de los arts. 14.2 y 68.4 LPAC, pues considera que no le resulta necesario para la resolución del recurso. Basa su razonamiento en la interpretación restrictiva y, a nuestro juicio, hartamente discutible por los flancos que abre, de los términos «solicitud» y «solicitudes», empleados por el art. 68.4 LPAC y sobre los que más adelante volveremos. Declara a este respecto que.

«La confirmación del pronunciamiento del Tribunal sentenciador, respecto de la anulación de la Orden de la Consejería de Economía y Hacienda de 20 julio de 2018 hace innecesario que nos pronunciemos sobre el alcance de la disposición final séptima de la Ley 39/2015, de 1 de octubre, del Procedimiento Administrativo Común de las Administraciones Públicas, a los efectos de determinar la entrada en vigor de la previsión contenida en el artículo 14.2 de dicha norma, pues esta cuestión está directamente relacionada con la aplicabilidad del art. 68.4 del citado texto legal a los recursos administrativos, lo que hemos descartado en los precedentes razonamientos jurídicos».

Por consiguiente, ceñida la labor en casación del Tribunal Supremo a dar respuesta a una -la cuestión (i) - de las dos cuestiones planteadas en el trámite de admisión, se establece la siguiente doctrina legal con respecto a la interpretación del art. 68.4 LPAC:

«El apartado 4 del artículo 68 de la Ley 39/2015, de 1 de octubre, del Procedimiento Administrativo Común de las Administraciones Públicas, que dispone que si alguno de los sujetos a los que hace referencia el artículo 14.2 y 14.3 presenta su solicitud presencialmente, las Admi-

11 «Planteada en estos términos la controversia y teniendo en cuenta que, junto al artículo 88.2 c) LJCA, el Letrado de los Servicios Jurídicos de la Comunidad Autónoma, invoca la concurrencia de la presunción prevista en el artículo 88.3 a) LJCA, nos corresponde verificar si las cuestiones apuntadas se encuentran revestidas de interés casacional objetivo para la formación de jurisprudencia. Y la respuesta ha de ser afirmativa puesto que lo suscitado no carece manifiestamente de interés casacional (esto es, de una forma evidente y sin complejos razonamientos jurídicos) trascendiendo del mero objeto del pleito la interpretación que deba darse a los artículos 14.2 y 68.4 LPAC a los efectos de determinar cuáles son las consecuencias que se derivan del requerimiento de subsanación que prevé el segundo de los citados preceptos cuando no se ha cumplido con la obligación de relación a través de medios electrónicos que impone el primero de ellos. Se trata, en particular, de determinar si, una vez subsanado el defecto y presentado el recurso por medios electrónicos, la subsanación es retroactiva (como entiende la Sala) o fija el día en que haya de entenderse cumplimentado el trámite de que se trate. Todo ello permitirá también aclarar lo relativo a la vigencia de las normas que resulten de aplicación, de acuerdo con lo establecido en la Disposición final séptima de la Ley de Procedimiento Administrativo Común de las Administraciones Públicas. No existe sobre estas cuestiones jurisprudencia de esta Sala y parece conveniente un pronunciamiento al respecto, concurriendo, por tanto, las circunstancias invocadas por la recurrente» [Razonamiento Jurídico 2 a)].

En línea con lo formulado, el TS razona también en este mismo apartado que, anteriormente por Providencia de 3 de julio de 2019 , había inadmitido a trámite el recurso de casación núm. 647/2019, preparado por la Letrada de la Comunidad Autónoma de Castilla y León contra la Sentencia del TSJ de 30 de octubre de 2018 , puesto que nada se razonó acerca del principio de vinculación a los actos propios. 
REALA. Nueva Época - N. 16, octubre 2021 - ISSN: 1989-8975 - DOI: https://doi.org/10.24965/reala.i16.10990 - [Págs. 134-149]

Un comentario a propósito del art. 68. 4 de la Ley de Procedimiento Administrativo Común y de la sentencia de casación de la sala...

Mariano López Benítez / Patricia Soriano Bautista

nistraciones Públicas requerirán al interesado para que la subsane a través de su presentación electrónica, y que a estos efectos, se considerará como fecha de presentación de la solicitud aquella en la que haya sido realizada la subsanación, resulta aplicable a la fase inicial de los procedimientos administrativos iniciados a instancia de los interesados».

Esta doctrina legal es síntesis de un razonamiento más extenso del Tribunal que, por un lado, en aplicación de los principios antiformalista y de subsanabilidad rechaza cualquier interpretación de los arts. 14.2 y 68.4 LPAC «que prive de validez y eficacia al acto originario de presentación del recurso de alzada»; $y$, por otro lado, restringe la aplicación de las consecuencias de este último precepto a los procedimientos iniciados a solicitud del interesado, con exclusión, por tanto, de «los procedimientos iniciados de oficio por la Administración (...y de) los procedimientos de revisión de los actos administrativos»:

«Sostenemos -dice el TS- que no resulta convincente la tesis argumental que desarrolla el Letrado de la Comunidad Autónoma de Castilla y León, que postula la aplicación generalizada de la previsión contenida en el artículo 68.4 de la Ley 39/2015, en aras de incentivar el cumplimiento de la obligación de relacionarse con la Administración por medios electrónicos contemplada en el artículo 14.2 del citado texto legal, por cuanto no hay -según se aducediferenciación de objetos entre el procedimiento administrativo común y los procedimientos revisorios, pues no tiene en cuenta que el instituto procedimental de la subsanación no puede comportar para el interesado que cumple en tiempo y forma el requerimiento efectuado por la Administración unas consecuencias jurídicas lesivas del derecho a la protección jurídica, que constituye uno de los postulados nucleares de la configuración del Estado social y democrático de Derecho, en contravención del deber de buena administración».

No obstante, las incógnitas suscitadas por esta Sentencia del Tribunal Supremo son numerosas hasta el punto de que, como decíamos al inicio, no resultaría nada extraño que, con ocasión del planteamiento de otros nuevos recursos de casación, haya de aclarar algunas cuestiones relativas a la interpretación de los arts. 14.2 y 68.4 LPAC que la sentencia comentada ha dejado en penumbra. Sorprende, en particular, que la sentencia sea muy parca a la hora de explicar cómo juega aquí el principio de vinculación de la Administración a los actos propios. Y la sorpresa es aún mayor no sólo porque la apelación a este principio es una de las piezas estelares de la sentencia recurrida, sino porque, como reconocía el propio Auto de Admisión, la falta de toda referencia a tal principio por parte de los proponentes de un anterior recurso de casación fue, precisamente, la causa que motivó su inadmisión ${ }^{12}$.

Según ya hemos anticipado, hay que ir al cuerpo de la sentencia para advertir que el TS está restringiendo el ámbito de aplicación del art. 68.4 LPAC únicamente a las solicitudes en sentido estricto, esto es, a los escritos que inician el procedimiento administrativo, o por así llamarlo, a las solicitudes de los administrados iniciadores de un procedimiento administrativo ex novo o de instancia. Los procedimientos revisorios -como la sentencia los denomina- quedan, por consiguiente, fuera del campo de aplicación del art. 68.4 LPAC. Y quedan fuera porque no sólo no son solicitudes originales, sino porque, aunque también sean escritos del administrado -los escritos de recurso- que inician un procedimiento administrativo propio y substantivo, se encuentran vinculados a un acto administrativo previo, nacido de un procedimiento administrativo anterior tramitado bien de oficio, bien a instancia de parte. A mayores, el significado otorgado por la sentencia a la noción de «procedimiento revisorio» es muy amplio, pues hay que entender que abraza tanto los recursos administrativos en sentido estricto (los ordinarios de alzada y reposición e, incluso, el extraordinario de revisión), como también las diversas manifestaciones de procedimientos revocatorios a los que se alude en el capítulo I del Título V LPAC, es decir, las solicitudes de revisión de oficio y de revocación y rectificación de actos administrativos.

12 «Somos conscientes de que nos apartamos de lo acordado en la providencia de 3 de julio de 2019 que inadmitió a trámite el recurso de casación núm. 647/2019, preparado por la Letrada de la Comunidad Autónoma de Castilla y León contra la Sentencia de la Sala de lo Contencioso-administrativo (sección primera) del Tribunal Superior de Justicia de Castilla y León (sede en Valladolid), de 30 de octubre de 2018, por la que se desestimaba el recurso de apelación núm. 365/2018 en materia sustancialmente idéntica. Reconsideración que obedece a que, en este caso, al contrario de lo que sucedía en el citado recurso de casación núm. 647/2019 en el que nada se razonó en relación con el primer argumento de la sentencia relativo a la vulneración por la Administración autonómica del principio de vinculación a los actos propios, sí se ha razonado en este caso que de los hechos acontecidos no puede derivarse la aplicación de la doctrina de los actos propios de la Administración» [Razonamiento Jurídico $2 .^{\circ}$ del Auto de la Sala de Admisión del Tribunal Supremo de 18 de diciembre de 2020 (rec. cas. 1928/2020), Ponente: Arozamena Laso, ECLI:ES:TS:2020:12753A]. 
REALA. Nueva Época - N. 16, octubre 2021 - ISSN: 1989-8975 - DOI: https://doi.org/10.24965/reala.i16.10990 - [Págs. 134-149]

Un comentario a propósito del art. 68. 4 de la Ley de Procedimiento Administrativo Común y de la sentencia de casación de la sala...

Mariano López Benítez / Patricia Soriano Bautista

Aunque la finalidad justificativa de tamaña identificación sea -como la sentencia confiesa- la de preservar el «derecho a la protección jurídica» de las nefandas y «lesivas consecuencias jurídicas» del art. 68.4 LPAC, lo cierto es que esta protección jurídica del administrado puede verse cercenada asimismo cuando, por aplicación del art. 68.4 LPAC, se le prive al interesado de la posibilidad de optar a una ayuda o prestación -cuya solicitud responda no a una convocatoria o procedimiento de oficio ad hoc, sino a unas previsiones temporales preestablecidas ya con carácter general e indefinido por una Ley o por un Reglamento-13; o cuando, por obra de aquel precepto, se frustre el planteamiento temporal de una solicitud de responsabilidad patrimonial ${ }^{14}$; o cuando, en un plano más doméstico, determine la pérdida de la preferencia temporal de mejor derecho para optar a una concesión o autorización ${ }^{15}$. La argumentación empleada por el Tribunal Supremo para extraer los procedimientos revisorios del ámbito de aplicación del art. 68.4 LPAC, es, por tanto, reversible y susceptible de referirse igualmente a las solicitudes en sentido estricto, tal y como esta decisión judicial las concibe.

Mas, no son las anteriores las únicas incertidumbres que planean sobre la sentencia comentada. $\mathrm{Si}$, a los efectos de la aplicación del art. 68.4 LPAC, los procedimientos administrativos en vía de recurso (o los revisorios, en general) pierden su autonomía y substantividad procedimentales con respecto a los procedimientos de instancia, significa ello que la obligación de relacionarse electrónicamente con la Administración -consagrada para determinados interesados por el art. 14.2 LPAC- pierde, en puridad, su naturaleza jurídica obligacional con respecto a los procedimientos revisorios, puesto que queda desprovista de cualquier consecuencia jurídica onerosa u ablatoria para el recurrente. Ni tan siquiera se transforma en una carga, porque la carga se contrae a la voluntad de interponer o no el recurso, pero no a la forma en que el recurrente decida presentar el recurso mismo, cuestión absolutamente indiferente en tanto en cuanto el recurrente, careciendo la obligación de relacionarse electrónicamente con la Administración de cualquier consecuencia jurídica, puede optar libremente por presentar su recurso telemáticamente o por presentarlo en papel, sin que de tal decisión se derive perjuicio jurídico alguno y aunque venga obligado a hacerlo de manera electrónica por ministerio del art. 14.2 LPAC. Es decir, la obligación de relacionarse electrónicamente con la Administración, impuesta para determinadas personas, entes y grupos por el art. 14.2 LPAC, no es una obligación general e indiscriminada, aplicable con respecto a todos los actos y procedimientos administrativos. Con respecto a los que la sentencia denomina procedimientos revisorios, tal obligación no rige, o, si rige, lo hace a título de obligación natural, esto es, sin consecuencia jurídica que sancione o grave su incumplimiento. La propia sentencia lo reconoce sin tapujos, emplazando incluso al legislador para que remedie tal entuerto:

«Cabe significar al respecto, que el deber de la Administración de respetar el derecho al procedimiento debido, cuya constitucionalización como principio rector de la organización y funcionamiento de las Administraciones Públicas se deriva del artículo 103 de la Constitución, impone (a falta de una previsión normativa con rango que regule de forma específica las consecuencias que con carácter general origine el incumplimiento de la obligación de relacionarse con la Administración a través de medios electrónicos, a los efectos de determinar la fecha en que debe considerarse presentado el recurso administrativo, que, sede materiae, debería establecerse

13 En el ámbito de la agricultura no es infrecuente encontrarse ante tipos de ayudas anuales que no son objeto de convocatorias anuales específicas, sino que la periodicidad y el plazo de su presentación está fijado en la propia norma que establece y regula la ayuda, una norma que, en algunos casos, no es nacional, sino comunitaria y que además impone la presentación telemática de las solicitudes por tratarse de actos-masa. En tales supuestos, salvo que forzásemos hasta el extremo el concepto de procedimiento abierto de oficio hasta hacerlo dimanar tácita o implícitamente de la propia norma reguladora, parece que nos encontraríamos ante solicitudes que entrarían plenamente dentro del ámbito de aplicación del art. 68.4 LPAC.

14 Las varias aportaciones de los blogistas reseñadas en nota 1, aluden expresamente a este ejemplo de la solicitud de responsabilidad patrimonial, cuyo ejercicio, aun careciendo de plazo concreto, sí que está sujeta en todo caso al plazo de prescripción del año previsto por el art. 67 LPAC, lo que suscita y plantea numerosas dudas que no podemos tratar en el marco de este comentario, como la relativa a si la presentación presencial de una reclamación de responsabilidad por quien está obligado a hacerlo electrónicamente interrumpe o no la prescripción.

15 Aun no estando sujeta la presentación a plazo, esto último puede darse, por ejemplo, en materia de solicitud de registro de marcas para el caso de que se insten dos solicitudes idénticas con respecto a una misma clase de productos, en donde tanto la normativa reguladora como la jurisprudencia hacen una aplicación del principio prior tempore, potior iuris. Como a este respecto señala la STSJ de Galicia núm. 282/2013, de 27 de febrero, rec. cont-advo 8095/2009, Ponente: Quintas Rodríguez, ECLI:ES: TSJGAL:2013:1609: «La expresión anteriormente solicitado o registrado, ha de interpretarse por su parte no en el sentido ....solicitado prioritariamente... sino en el de haber solicitado o estar registrado en el tiempo otros antes de solicitar la marca». Con carácter general, debe recordarse además lo que establece el art. 71.2 de la propia LPAC: «En el despacho de los expedientes se guardará el orden riguroso de incoación en asuntos de homogénea naturaleza». 
REALA. Nueva Época - N. 16, octubre 2021 - ISSN: 1989-8975 - DOI: https://doi.org/10.24965/reala.i16.10990 - [Págs. 134-149]

Un comentario a propósito del art. 68. 4 de la Ley de Procedimiento Administrativo Común y de la sentencia de casación de la sala...

Mariano López Benítez / Patricia Soriano Bautista

en el artículo 14 de la Ley 39/2015), que se interpreten las normas procedimentales que regulan la interposición de recursos administrativos previos a entablar acciones ante los órganos de la Jurisdicción contencioso-administrativa con los mismos criterios hermenéuticos formulados por el Tribunal Constitucional y por este Tribunal Supremo para garantizar y asegurar el derecho a la tutela judicial efectiva, en los términos del artículo 24 de la Constitución».

Si damos un paso más y nos adentramos en lo que, según la sentencia, constituye el campo natural de aplicación del art. 68.4 LPAC, esto es, el de las solicitudes de instancia, las dudas afluentes no son menores, especialmente porque, como avanzábamos, la sentencia prescinde de toda consideración con respecto al papel que en este ámbito pueden desplegar principios como el de la vinculación de la Administración a sus propios actos y el de la confianza legítima. $Y$ es que el juego de tales principios se encuentra muy vinculado en nuestro caso al sentido que otorguemos al requerimiento previsto en el art. 68.4 LPAC. Recordemos, de nuevo, lo que determina el precepto:

«Si alguno de los sujetos a los que hace referencia el artículo 14.2 y 14.3 presenta su solicitud presencialmente, las Administraciones Públicas requerirán al interesado para que la subsane a través de su presentación electrónica. A estos efectos, se considerará como fecha de presentación de la solicitud aquella en la que haya sido realizada la subsanación».

Aparentemente, lo que se desprende de la lectura literal del precepto es que, cuando un sujeto, incumpliendo la obligación de relacionarse electrónicamente con la Administración, presenta una solicitud presencialmente, debe ser siempre requerido para que subsane la forma de presentación de su escrito. Si la formulación del requerimiento, prescindiendo de la fecha en que se haya producido la presentación presencial, deviene siempre obligatoria para la Administración, lo que no se advierte es la finalidad y utilidad del propio art. 68.4 LPAC, cuya existencia entonces carece de sentido, ya que el hecho de que su solicitud sea o no admitida a trámite no va a depender del requerimiento que le dirija la Administración, sino de que el interesado cuente con plazo suficiente aún para presentar electrónicamente su instancia. Si dispone aún de plazo, bien porque el plazo de presentación no haya finalizado todavía o bien porque se trate de procedimientos abiertos no sujetos a plazo de presentación, la admisión de su solicitud nada tendrá que ver con el requerimiento que le haya formulado la Administración; requerimiento que, en el mejor de los casos, no pasará de ser el mero recordatorio de una obligación -la de relacionarse electrónicamente con la Administración (art. 14.2)-, y, desde luego, no la consecuencia jurídica que la respalda.

A esta interpretación lleva conceptuar el requerimiento como un requerimiento, en todo caso, obligado para la Administración, comprensión a la que, desde luego, dan pábulo los rotundos e imperativos términos en que se pronuncia al respecto el art. 68.4 LPAC: «las Administraciones Públicas requerirán al interesado». Sin embargo, el carácter obligado de este requerimiento puede tener otra lectura si se le conecta con los antedichos principios de confianza legítima y de vinculación de la Administración a sus propios actos. Una lectura que, como demuestra el examen de la jurisprudencia menor analizada anteriormente, puede subvertir por completo el significado del propio art. 68.4 LPAC y hacerlo aún más incomprensible e innecesario.

Por ejemplo, si, siguiendo la práctica habitual y más frecuente entre los administrados, esperamos al último día de plazo de una convocatoria para presentar nuestra solicitud y lo hacemos presencialmente, aun estando obligados a efectuarla telemáticamente ${ }^{16}$, por muy diligente que sea la Administración competente a la hora de realizar el requerimiento, es más que probable que nuestra subsanación electrónica llegue tarde

16 No debe olvidarse que el elenco de obligados a relacionarse electrónicamente con la Administración no sólo abarca los que se enumeran en el art. 14.2 LPAC, sino que su número puede incrementarse con carácter general o puntualmente para determinados procedimientos, en virtud de lo previsto por el apartado $3 .^{\circ}$ de este mismo precepto, «reglamentariamente, las Administraciones podrán establecer la obligación de relacionarse con ellas a través de medios electrónicos para determinados procedimientos y para ciertos colectivos de personas físicas que por razón de su capacidad económica, técnica, dedicación profesional u otros motivos quede acreditado que tienen acceso y disponibilidad de los medios electrónicos necesarios». Un precepto, por cierto, cuyos términos de remisión tan amplios, han vuelto a ser objeto de atención por el Consejo de Estado en su reciente Dictamen núm. 45/2021, de 18 de marzo, con ocasión del desarrollo llevado a cabo por el Reglamento de Actuación y Funcionamiento del Sector Público por medios electrónicos. Advierte, en concreto, el Consejo de Estado que, «durante la tramitación del expediente se ha planteado en varias ocasiones la necesidad de desarrollar las previsiones del articulo 14.3 de la Ley 39/2015, (...). Finalmente, los ministerios proponentes han optado por no concretar en el texto propuesto ninguna obligación especifica de uso de medios electrónicos en el ámbito estatal, sino por remitir su desarrollo a otras normas reglamentarias que se adopten en el futuro, bien como real decreto acordado en Consejo de ministros, bien mediante orden ministerial. Parece, sin embargo, al Consejo de Estado que la redacción del articulo 3.3, párrafo segundo, resulta excesivamente abierta, en cuanto no concreta los criterios que permitan diferenciar cuándo deberá imponerse la obligación mediante real decreto ni cuándo bastará con una orden ministerial. Habida cuenta de la trascendencia de esta regulación para los sujetos afectados, 
REALA. Nueva Época - N. 16, octubre 2021 - ISSN: 1989-8975 - DOI: https://doi.org/10.24965/reala.i16.10990 - [Págs. 134-149]

Un comentario a propósito del art. 68. 4 de la Ley de Procedimiento Administrativo Común y de la sentencia de casación de la sala...

Mariano López Benítez / Patricia Soriano Bautista

y, cuando la hagamos, el plazo de vencimiento ya haya transcurrido. Si con certeza la Administración sabe que, cuando subsanemos, la fecha de subsanación -que determina también, según el art. 68.4, la fecha de presentación de la solicitud-será posterior a la expiración del plazo de vencimiento de la convocatoria, ¿qué sentido tendrá, entonces, el requerimiento formulado por la Administración? Aún más ilógico resultará el requerimiento si, cuando éste se realice, el plazo de presentación ya ha pasado, por ejemplo, porque registrásemos nuestra solicitud extemporáneamente.

Efectivamente, ambas situaciones no son idénticas. No es lo mismo que la instancia se haya presentado presencialmente en plazo a que lo haya sido transcurrido éste. Con respecto a esta última situación, lo procedente sería no ya formular el requerimiento al que alude el art. 68.4 LPAC, sino dictar una resolución inadmitiendo por extemporánea la solicitud. Por el contrario, en lo concerniente a la otra situación, la presentación presencial en plazo ${ }^{17}$ puede deberse a distintas causas: desde el propósito deliberado de burlar la obligación establecida por el art. 14.2 -lo que, asimismo, puede redundar en una vulneración del principio de igualdad y no discriminación, ya que la presentación en condiciones distintas a las legalmente exigidas y la subsanación pueden suponer una ampliación de plazo que iría en perjuicio de los demás solicitantes, que sí han cumplido su obligación presentando la solicitud electrónicamente ${ }^{18}$ - hasta razones que escapan a la voluntad y disposición del administrado, como la falta de conectividad de sus equipos informáticos, la sobresaturación de las redes administrativas de recepción y registro $u$ otras circunstancias de fuerza mayor ${ }^{19}$. En tales ocasiones, el requerimiento obligado de la Administración sí adquiere sentido. Lo que no tiene sentido, en cambio, es que los efectos derivados de la atención a dicho requerimiento se constriñan principalmente a que «se considerará como fecha de presentación de la solicitud aquella en la que haya sido realizada la subsanación». Por el interés que posee en la ponderación de esas circunstancias concurrentes y, aunque es harto dudoso que las soluciones propugnadas por la LPAC resulten extensibles a los procedimientos electrónicos contractuales, podemos aquí traer a colación la Resolución 602/2020, de 14 de mayo de 2020, del Tribunal Administrativo Central de Recursos Contractuales recaída en el recurso 276/2020 resume la doctrina de este Tribunal respecto a la presentación extemporánea de ofertas:

sería oportuno que la norma proyectada recogiera con mayor precisión los criterios que permitan determinar cuándo deberá establecerse la obligación mediante real decreto acordado en Consejo de ministros y cuándo podrá hacerse a través de orden ministerial».

17 En el campo de la licitación electrónica se ha planteado la posibilidad de que en un procedimiento de licitación electrónica sea presentada una oferta en papel, y si en este caso sería posible conceder un plazo de subsanación para que la proposición sea presentada por vía electrónica. A estas preguntas responde el Informe 2/2018, emitido por la JCCPE ante una consulta formulada por la Universidad de Córdoba; se refiere esta consulta a la posibilidad de subsanación conforme a lo establecido en el artículo 68.4 de la LPAC respecto de una oferta presentada de forma manual; si la presentación electrónica podría presentarse una vez finalizado el plazo de presentación de ofertas a través de la herramienta de presentación de ofertas; y de no ser posible la presentación a través de esta herramienta, de qué otra forma podría presentarse. Respecto de la primera de las cuestiones planteadas, señala el informe que «la conclusión es que a partir de la entrada en vigor de la Ley 9/2017 la regla general para la presentación de las ofertas es la utilización de los medios electrónicos, que sólo cede ante los casos tasados previstos en la citada disposición adicional decimoquinta de la Ley 9/2017, debiendo en cualquier caso justificarse la excepción de forma expresa, al exigirse que "los órganos de contratación indicarán en un informe específico las razones por las que se haya considerado necesario utilizar medios distintos de los electrónicos." (DA Decimoquinta, apartado 3 y 4 in fine)». En lo que afecta al trámite de subsanación añade que: «Hay que tener en cuenta además que, establecida la obligación para todos los licitadores de presentar electrónicamente las proposiciones, no tiene sentido la aplicación del otorgamiento de un trámite de subsanación para aquellos que, incumpliendo la obligación legal, presentan la documentación en papel, beneficiándose de algún tipo de ventaja, como una posible ampliación singular del plazo para presentar las proposiciones por la vía exigida legalmente». Y concluye que «en los procedimientos de licitación en los que resulte obligatoria la presentación de ofertas por medios electrónicos, no resulta de aplicación supletoria a la presentación de ofertas el trámite previsto en el artículo 68.4 de la Ley 39/2015, de 1 de octubre, del Procedimiento Administrativo Común de las Administraciones Públicas, porque no existe una laguna legal que motive la aplicación del precepto y porque resulta incompatible con los principios de publicidad, transparencia, igualdad de trato y no discriminación que inspiran la regulación de los procedimientos de licitación regulados en la misma».

${ }_{18}$ Y sin olvidar que el artículo 68.4 debe ser relacionado con el 16.8 de la misma Ley, y según el cual «no se tendrán por presentados en el registro aquellos documentos e información cuyo régimen especial establezca otra forma de presentación», por lo que la solicitud presentada de forma presencial por un sujeto obligado electrónicamente, debe considerarse como no presentada.

19 En esta materia, debemos hacer referencia a la Plataforma de Contratación del Sector Publico, dado que se han suscitado numerosos problemas derivados de la presentación electrónica de ofertas, y los fallos técnicos de la plataforma cuando estos tengan repercusión sobre la presentación de ofertas. Ha sido fundamentalmente el Tribunal Administrativo Central de Recursos Contractuales el que ha fijado doctrina a través de sus resoluciones. Este Tribunal, entre otras Resoluciones 560/2018 de 8 de junio, $595 / 2018$, de 21 de junio, 696/2018, de 20 de julio, 1178/2018, de 18 de diciembre, en las que se reconoce que ha existido imposibilidad de presentar la oferta en plazo por problemas técnicos de la plataforma; señala que la Administración tiene dos opciones: ampliar el plazo de presentación de ofertas, o admitir el uso de otros medios para la presentación de ofertas; lo importante es que quede acreditada tanto la imposibilidad de presentar las ofertas a través de la PCSP, como que los problemas técnicos no sean imputables al propio licitador, a fin de que quede garantizado el principio de igualdad y no discriminación entre los licitadores, lo que tendría lugar cuando se permite a un licitador presentar una oferta fuera del plazo y condiciones que rigen para el resto de licitadores. 
REALA. Nueva Época - N. 16, octubre 2021 - ISSN: 1989-8975 - DOI: https://doi.org/10.24965/reala.i16.10990 - [Págs. 134-149]

«El Tribunal ha tenido ocasión de pronunciarse sobre inadmisiones de ofertas producidas como consecuencia de su presentación al límite de la finalización del plazo para su. presentación en la Plataforma de Contratación en diversas resoluciones. Decíamos recientemente en la Resolución 924/2019, de 1 de agosto, y en la Resolución 1235/2019, de 4 de noviembre, lo siguiente ... en la Resolución 696/2018 desestimamos igualmente el recurso, confirmando la exclusión de la licitación de una empresa que habría advertido de la existencia de errores técnicos minutos antes de que finalizara el plazo para ello, sin dejar, en consecuencia, el "margen temporal necesario para poder detectar y solventar el problema denunciado".

El principio de igualdad y no discriminación impone el respeto de las condiciones establecidas para participar en las licitaciones públicas, sin excepciones ni distinciones entre los licitadores, de modo que, por principio, una oferta presentada fuera de plazo ha de ser inadmitida por la Administración, a menos que el interesado acredite de forma indubitada que la extemporaneidad de la presentación respondió a causas que no le son en modo alguno imputables a el, sino a la propia Administración que redactó los pliegos.

En el supuesto examinado, en ausencia de una prueba que acredite el mal funcionamiento de la Plataforma, sólo la recurrente es la responsable de no haber podido participar en la licitación, pues fue ella quien consumió prácticamente la totalidad del plazo, quedándose sin capacidad de respuesta ante cualquier incidente informático similar naturaleza que pudiera plantearse».

\section{REFLEXIONES FINALES}

La Sentencia del Tribunal Supremo, que enmarca el presente comentario, recuerda muy pertinentemente en su fundamento de derecho segundo la doctrina jurisprudencial que el Alto Tribunal tiene establecida con respecto a los requerimientos de la Administración:

«En relación con la interpretación del artículo 71 de la Ley 30/1992, de 26 de noviembre, de Régimen Jurídico de las Administraciones Públicas y del Procedimiento Administrativo Común, en la sentencia de esta Sala de lo Contencioso-Administrativo del Tribunal Supremo de 16 de diciembre de 2018 (RC 2986/2016), se consagra de forma implícita el principio pro actione como canon hermenéutico para determinar el alcance de los requerimientos efectuados por la Administración al interesado para que subsane cualquier defecto advertido en la presentación de la solicitud».

Aunque, en sentido estricto, el requerimiento exigido por el art. 68.4 no se corresponde directamente con los requerimientos expresados por el antiguo art. 71 LRJPAC (en la actualidad, previstos en el art. 68.1 LPAC), lo que sí es verdad es que ambos se nutren y dimanan de un supraconcepto común: el principio pro actione. Por ello, parece poco acorde con esta doctrina que, en los casos en que el administrado presenta presencialmente su solicitud y es requerido por la Administración para su correcta presentación telemática, los efectos derivados de atender tal requerimiento se desgajen y desvinculen absolutamente de las consecuencias naturales del principio pro actione, ofreciendo una respuesta legal claramente contraria a la naturaleza de este principio y a la confianza legítima generada por el requerimiento en el administrado.

Precisamente, por mor de esta vinculación, carece de toda lógica que, atendiendo a los imperativos términos del art. 68.4, la Administración tenga que formular siempre requerimiento de presentación electrónica. Es más, como ha puesto de relieve algún Tribunal Superior de Justicia ${ }^{20}$, en los casos en que la presentación presencial se hubiera producido extemporáneamente, se correría el riesgo de que, por la vinculación de la Administración a sus propios actos, se reabriesen unos plazos, ya fenecidos, lo que, a todas luces, constituiría un fraude legal perpetrado por la Administración. Por consiguiente, no coloca el art. 68.4 LPAC en una posición cómoda a la Administración ante estos casos.

Mas, fuera ya de esta hipótesis y concluyendo con nuestro comentario a la Sentencia de casación del Tribunal Supremo núm. 954/2021, creemos que resulta difícil mantener que el art. 68.4 LPAC sea la consecuencia jurídica inmediata al incumplimiento de la obligación prevista por el art. 14.2. La meritada Sentencia ya ha desmontado tal carácter con respecto a lo que ella denomina procedimientos revisorios, los cuales quedarían

20 STSJ de Valencia núm. 93/2020, de 18 de febrero (rec. 42/2018). Ponente: Pérez Padilla. ECLI:ES: TSJCV:2020:2533. 
REALA. Nueva Época - N. 16, octubre 2021 - ISSN: 1989-8975 - DOI: https://doi.org/10.24965/reala.i16.10990 - [Págs. 134-149]

Un comentario a propósito del art. 68. 4 de la Ley de Procedimiento Administrativo Común y de la sentencia de casación de la sala...

Mariano López Benítez / Patricia Soriano Bautista

fuera de su ámbito de aplicación por no tratarse, en puridad, de solicitudes. Por nuestra parte, y con respecto a éstas, tampoco estimamos que, pese a los aparentes, rotundos e imperativos términos empleados por el art. 68.4 , este precepto sea la consecuencia jurídica aplicable inexorablemente a los casos en que un obligado a relacionarse electrónicamente con la Administración presenta una solicitud en forma distinta a la telemática. En nuestra opinión, su naturaleza, como mucho, se halla más próxima al de una simple presunción, desmontable en función de las circunstancias concurrentes, y, a través también del juego combinado en cada caso de los principios pro actione, de vinculación de la Administración a sus propios actos y de confianza legítima.

Tampoco el art. 14.1 del reciente Reglamento de Actuación y Funcionamiento del Sector Público por Medios Electrónicos (RD 203/2021, de 30 de marzo) facilita la interpretación del art. 68.4 LPAC. Lejos de contribuir a su aclaración, lo que, a nuestro juicio, ha hecho, ha sido homologar la naturaleza jurídica de este requerimiento de presentación telemática con la de los otros requerimientos de subsanación contemplados en el art. 68. En este sentido, en primer lugar, comienza fijando el plazo de diez días para atender el requerimiento, y señalando expresamente que, si no se atiende, se le tendrá por desistido de su solicitud o se le podrá declarar decaído de su derecho al trámite; para luego terminar remitiéndose a los efectos del art. 68.4 LPAC en lo que respecta a las solicitudes de iniciación. Dice el art. 14.1 del citado Reglamento que:

«Si existe la obligación del interesado de relacionarse a través de medios electrónicos y aquel no los hubiese utilizado, el órgano administrativo competente en el ámbito de actuación requerirá la correspondiente subsanación, advirtiendo al interesado, o en su caso su representante, que, de no ser atendido el requerimiento en el plazo de diez días, se le tendrá por desistido de su solicitud o se le podrá declarar decaído en su derecho al trámite correspondiente, previa resolución que deberá ser dictada en los términos previstos en el artículo 21 de la Ley 39/2015, de 1 de octubre.

Este régimen de subsanación será asimismo aplicable a las personas físicas no obligadas a relacionarse a través de medios electrónicos con las Administraciones Públicas que, de acuerdo con lo dispuesto en el artículo 3.2, hayan ejercitado su derecho a relacionarse electrónicamente con la Administración Pública de que se trate.

Cuando se trate de una solicitud de iniciación del interesado, la fecha de la subsanación se considerará a estos efectos como fecha de presentación de la solicitud de acuerdo con el artículo 68.4 de dicha ley».

Aunque, como decimos, el precepto dista de ser claro y añade mayor complejidad interpretativa a la ya existente, sí creemos que, mediante la homologación que opera entre uno y otro tipo de requerimientos, su vinculación con el principio pro actione se hace aún más estrecha de cara a la hermenéutica del art. 68.4 LPAC. No resulta inoportuno traer aquí la argumentación sostenida a este respecto por la STSJ de Madrid 276/2018, de 29 de mayo, ante un caso en el que la Administración, invocando el art. 68.4 LPAC, había formulado un requerimiento de presentación telemática, determinando un plazo de diez días para atenderlo y señalando que, de no hacerlo, se le tendría por desistido de su solicitud. EI TSJ, subrayando la importancia y aplicación al caso de los principios de confianza legítima y de vinculación de la Administración a sus propios actos, estima el recurso y rechaza la inadmisión por extemporaneidad aplicada al acto del administrado:

«La Administración interpretó que, de conformidad con el artículo 68.4 de la Ley 39/2015, había de considerarse como fecha de presentación del escrito la fecha de presentación telemática, frente a la de presentación presencial (...).

Pero la concesión del plazo de diez días para subsanación del defecto, y el apercibimiento de tenerle por desistido de su pretensión, alteraron de tal forma el sentido del precepto, que la aplicación del párrafo cuarto debe considerarse sorpresiva y contraria al principio de confianza legítima, y a los propios actos de la Administración.

Porque el artículo 68 sólo establece el plazo de diez días de subsanación en el párrafo primero; previendo este plazo como un período en el que se admite propiamente la posibilidad de subsanar el defecto apreciado, con todos los efectos legales; lo que establece de forma coherente con la obligación de indicar al requerido que, en caso de no cumplimentación de lo ordenado, se le tendrá por desistido de su pretensión.

Por el contrario, el párrafo cuarto no menciona plazo alguno de subsanación, y es que, ni existe, ni es necesario. Porque si la fecha de presentación del escrito que se va a considerar, en todo caso, va a ser a la de su presentación telemática, no se trata de una subsanación propia, 
REALA. Nueva Época - N. 16, octubre 2021 - ISSN: 1989-8975 - DOI: https://doi.org/10.24965/reala.i16.10990 - [Págs. 134-149]

Un comentario a propósito del art. 68. 4 de la Ley de Procedimiento Administrativo Común y de la sentencia de casación de la sala...

Mariano López Benítez / Patricia Soriano Bautista

ya que la consecuencia del defecto es, de entrada, la de no tener por presentado el escrito. Y, por otra parte, la fijación de un plazo concreto para su presentación resulta inútil, pues, cuando se realice, esto es, cuando se presente de forma telemática, sin perjuicio del tiempo en que se haga, producirá los efectos que procedan.

Correlativamente a esta consecuencia, no se hace saber al interesado que se le puede tener por desistido en caso de no cumplimentar el requerimiento; porque no se puede tener por desistido a quien no ha solicitado, y la regulación legal lo que determina es el escrito en ningún caso va a producir efectos; más que, en su caso, el de determinar la obligación de la Administración de advertir al interesado del defecto existente» ${ }^{21}$.

Efectivamente, apurando aún más los argumentos de esta sentencia del TSJ madrileño, es obvio que con la presentación presencial de una solicitud se producen ya algunos efectos: obliga a la Administración a que formule al interesado un requerimiento de subsanación telemática. Luego, la solicitud existe, no es una mera entelequia. El Consejo de Estado ha observado muy acertadamente que, aunque el logro de la llamada Administración electrónica sea un logro loable y una aspiración deseable, porque su plena consecución facilitará la gestión pública y beneficiará al ciudadano, la Administración electrónica no puede convertirse, sin embargo, en un fin en sí misma. En opinión de nuestro alto órgano consultivo, no puede perderse de vista que la Administración electrónica constituye sólo un medio para hacer más eficaz la gestión administrativa, un medio que no puede servir de excusa para arrumbar o mermar injustificadamente los derechos y las garantías de los administrados ${ }^{22}$. No obstante, también tal vez sería aconsejable un cambio de actitud para adaptarse a la Administración electrónica, tanto por parte de los administrados como por parte de la propia Administración, porque esta nueva Administración implica una gran dependencia tecnológica, y cualquier fallo técnico sobrevenido puede evitar que la presentación se haga en plazo. Para reforzar el desiderátum de que todos los obligados a relacionarse electrónicamente con la Administración lo hagan efectivamente, no creemos necesario poner en práctica el ardid que postula, como consecuencia jurídica, la aplicación del art. 68.4 LPAC: el que, por fecha de presentación de la solicitud, se tenga la de la subsanación telemática y no la de su presentación presencial. Presentación ésta última que existe y que ha permitido a la Administración conocer el contenido de la solicitud, hasta el punto de que ha generado obligaciones concretas para la Administración. Por tanto, ¿es proporcional y está justificado que, para fomentar el cumplimiento de una obligación por parte de los administrados, se aplique una consecuencia jurídica tan extrema como la señalada por el art. 68.4 LPAC? ¿No bastaría con que al requerimiento de subsanación telemática se le diese el mismo tratamiento jurídico que se le otorga a los restantes requerimientos de subsanación? ¿Es lógico que un hecho objetivo y real -como el de la presentación presencial de la solicitud- a la vez exista y no exista para la Administración?

La Sentencia de Casación del Tribunal Supremo 954/2021 ha aportado algunos importantes argumentos de cara a la interpretación del art. 68.4 LPAC. No obstante, son muchas las dudas interpretativas que, como hemos tratado de exponer, aún persisten y que, probablemente, den ocasión a nuevas decisiones del Alto Tribunal a través de la vía casacional. Sin embargo, los problemas interpretativos suscitados por el art. 68.4 LPAC (y agravados por el reciente Reglamento de desarrollo) son, a nuestro juicio, tan arduos e intrincados que tal vez justificarían y harían conveniente una reforma legislativa del art. 68.4 LPAC.

\section{REFERENCIAS BIBLIOGRÁFICAS}

Aparicio, E. (18 de julio de 2021). El TS concluye que el artículo 68.4 de la LPAC no es aplicable a los procedimientos iniciados de oficio, ni los de revisión de los actos administrativos [entrada de blog]. https://www.emilioaparicio. eu/emilioapariciosantamaria/el-ts-concluye-que-el-artculo-684-de-la-Ipac-no-es-aplicable-a-los-procedimientosiniciados-de-oficio-ni-a-los-de-revisin-de-los-actos-administrativos

Chaves García, J. R. (28 de febrero de 2018). La controvertida subsanación electrónica. https://delajusticia. com/2018/02/28/la-controvertida-subsanacion-electronica/

21 La STSJ de Madrid núm. 276/2018, de 29 de mayo, rec. núm. 251/2017. Ponente: Rivas Moreno. ECLI:ES: TSJM: 2018:7644. Pese a que la sentencia se refiere a un recurso de alzada y no a una solicitud, debe destacarse que, no sólo es anterior al fallo del Tribunal Supremo, sino que los argumentos empleados tienen validez y aplicación con independencia de que se trate de un recurso o de una simple solicitud.

22 Véanse los Dictámenes núms. 275/2015, de 29 de abril (referido al Anteproyecto de Ley de Procedimiento Administrativo Común) y 45/2021, de 18 de marzo (recaído con respecto al Reglamento de Actuación y Funcionamiento del Sector Público por medios electrónicos). 
Chaves García, J. R. (6 de septiembre de 2021). Suprema precisión sobre la subsanación de la obligación de relacionarse electrónicamente. https://delajusticia.com/2021/09/06/suprema-precision-sobre-la-subsanacion-de-laobligacion-de-relacionarse-electronicamente/

Cruz Ferrer J. de la y Trujillo Pérez, J. (2021). Comentario al artículo 68. En J. M. Baño León y J. J. Lavilla Rubira (dirs.), Comentarios al Procedimiento Administrativo. Tirant lo Blanch.

Gómez Fernández, D. (27 de febrero de 2018). La subsanación electrónica del art. 68.4 de la Ley 39/2015, de Procedimiento Administrativo. https://www.derechoadministrativoyurbanismo.es/post/2018/02/25/lasubsanacic3b3n-electrc3b3nica-del-art-684-de-la-ley-392015-de-procedimiento-administra

Gómez Fernández, D. (19 de julio de 2021). La subsanación electrónica del art. 68.4 LPAC sólo es para los procedimientos iniciados por solicitud. https://www.derechoadministrativoyurbanismo.es/post/lasubsanaci\%C3\%B3n-electr\%C3\%B3nica-del-art-68-4-Ipac-s\%C3\%B3lo-es-para-procedimientos-iniciados-porsolicitud

Rego Blanco, D. (2017). La presentación de solicitudes, escritos y documentos ante las Administraciones Públicas. En E. Gamero, S. Fernández Ramos y J. Valero (coords.). Tratado de Procedimiento Administrativo Común y Régimen Jurídico Básico del Sector Público. Tirant lo Blanch.

Zafra Romero, L. (23 de enero de 2020). Obligación de presentar recursos administrativos y relacionarse con Administraciones Públicas por medios electrónicos. Actualidad Jurídica Aranzadi, 959. 